\title{
SOBRE ANIMAIS, HUMANOS E MÁQUINAS: PARA ONDE VAI A CONSCIÊNCIA?
}

\author{
André Brayner de Farias ${ }^{1}$ \\ Universidade de Caxias do Sul (UCS) \\ (i) https://orcid.org/0000-0002-8659-3921 \\ E-mail: abraynerfarias@yahoo.com
}

\section{RESUMO:}

O artigo discute a relação entre humanos, animais e máquinas, tomando como foco o problema do desacoplamento da consciência implicado no desenvolvimento das inteligências artificiais. 'Que relação existe entre o progressivo condicionamento dos processos humanos aos processos artificiais (entidades inteligentes e não-conscientes) e a chamada ética animal?' e 'O que significa afirmar que a recente preocupação ética voltada para os animais é um fenômeno pós-histórico e biopolítico?' são algumas das interrogações que o artigo elabora e procura responder.

PALAVRAS-CHAVE: Animais; Humanos; Inteligência artificial; Consciência.

\section{ABOUT ANIMALS, HUMANS AND MACHINES: WHERE DOES CONSCIOUSNESS GO?}

\begin{abstract}
:
The article discusses the relantionship between humans, animals and machines, focusing on the problem of the decoupling of consciousness implied in the development of artificial intelligences. "What is the relationship between the progressive conditioning of human processes to artificial processes (intelligent and non-conscious entities) and the so-called animal ethics?' and 'What does it mean to say that the recent ethical concern for animals is a posthistorical and biopolitical phenomenon?' are some of the questions that the articles elaborates and tries to answer.
\end{abstract}

KEYWORDS: Animals; Humans; Artificial intelligence; Consciousness.

\footnotetext{
1 Doutor em Filosofia pela Pontifícia Universidade Católica do Rio Grande do Sul (PUCRS), Porto Alegre - RS, Brasil. Professor de Filosofia da Universidade de Caxias do Sul (UCS), Caxias do Sul - RS, Brasil.

FARIAS, André Brayner de. Sobre animais, humanos e máquinas: para onde vai a consciência? Griot : Revista de Filosofia, Amargosa - BA, v.20, n.2, p.1-24, junho, 2020.
} 
Talvez o corpo do animal antropóforo (o corpo do servo) seja o resto não resolvido que o idealismo deixa de herança ao pensamento e as aporias da filosofia de nosso tempo coincidam com as aporias desse corpo irredutivelmente teso e dividido entre animalidade e humanidade. (AGAMBEN, G. O aberto - o homem e o animal. p. 24-25)

\section{Introdução}

Dois temas bastante recorrentes no debate ético contemporâneo são o da relação entre humanos e animais e o da relação entre humanos e autômatos super-inteligentes, os robôs. Temas e áreas aparentemente desconectados, a ética animal e a cibernética, que, no entanto, fazem ressoar as questões provavelmente mais fundamentais para uma compreensão crítica da condição humana no presente e, principalmente, nos tempos que virão. Como chegamos a ter com os animais não humanos a relação que temos, basicamente de uma total desconsideração de seu valor, de sua sensibilidade e de sua consciência? E como chegamos, recentemente, a despertar para essas considerações: nem o valor moral, nem a senciência são privilégios humanos? Teríamos de fato começado a admitir o fim da nossa idade antropocêntrica, porque pouco a pouco passamos a achar razoável a ideia de incluir os animais no horizonte de nossas preocupações éticas? De fato, parece que há mais elementos em jogo quando se trata de proceder numa compreensão crítica da condição humana no presente e no futuro. Começar a admitir o fim da era antropocêntrica pode significar não somente o desinteressamento ontológico na direção de uma ética mais solidária com as outras formas de vida - menos evoluídas e nem por isso destituídas de sensibilidade e consciência; mas também a suspeita de que entidades artificiais super-inteligentes, e não necessariamente sensíveis e conscientes, possam vir a estabelecer com essas entidades inteligentes, e ainda conscientes e sensíveis, que são os animais humanos, padrões de relação não exatamente solidários. A compreensão crítica da condição humana não apontaria apenas para a mais que necessária revisão de nosso estatuto ontológico e ético na direção de uma forma mais harmoniosa de vida que considere o valor das outras formas de vida, mas também diz respeito à situação crítica de uma forma de inteligência prestes a ser ultrapassada por formas superiores. Nesse sentido, não caberia conjecturar que essa crítica ao antropocentrismo, aparentemente vinculada às éticas sensíveis ao apelo dos animais, no fundo ainda se mobiliza em nome de um humanismo já suficientemente informado de um futuro cibernético e pós-humano?

\section{Sobre animais, humanos e máquinas}

Em seu livro Homo Deus - uma breve história do amanhã, Yuval Noah Harari elabora diversas questões a respeito desse nosso amanhã cibernético e biotecnológico. $\mathrm{O}$ autor, em sua perspectiva macro-histórica, sustenta que a grande era dos humanismos está em seu ocaso e que estamos acelerando um processo onde haverá inevitavelmente uma virada pós-humanista. Faz parte do projeto humanista o desenvolvimento desenfreado da ciência e da tecnologia, e a biologia, a ciência mais importante no século XX, tem servido de modelo para o progressivo desenvolvimento de máquinas super-inteligentes. Estaríamos dando continuidade ao processo evolutivo, mas dessa vez para fora da cadeia do carbono, estaríamos evoluindo numa direção inorgânica, e dessa forma, elaborando não tão lentamente, afinal de contas o processo é visível e experienciável, o nosso ultrapassamento evolutivo. Esse processo é basicamente observável em nossa relação com os aparelhos, que configura aquilo que Vilém Flusser chama de condição póshistórica. 
Harari aponta para a importância de compreender o conceito de algoritmo: o novo salto evolutivo está condicionado ao entendimento de que todos os processos vitais resultam, no fundo, de uma determinada configuração de fatores, ou de uma receita, que são os tais algoritmos. Se tudo remete a algoritmos bioquímicos, por exemplo, e se tais algoritmos podem ser copiados por sistemas operacionais, isso implica que não importa mais tanto se a natureza do algoritmo é orgânica ou inorgânica, quanto se ele irá produzir o mesmo efeito. Coisas como emoções, sentimentos e experiências subjetivas na verdade não passam de efeitos algorítmicos. Para compreender a condição humana no século XXI, Harari recomenda que tenhamos suficiente paciência para entender esse conceito matemático que deverá estar por trás de todos os processos e comandos. $\mathrm{O}$ algoritmo, na verdade, é uma ordem de procedimentos. A melhor explicação do conceito é a que o compara a uma receita de sopa:

Um algoritmo para a preparação de uma sopa de legumes pode nos dizer:

1. Aqueça meia xícara de óleo numa panela.

2. Pique quatro cebolas em pedaços bem finos.

3. Frite as cebolas até ficarem douradas.

4. Corte três batatas em pedaços e acrescente à panela.

5. Corte um repolho em fatias e acrescente à panela.

E assim por diante. Pode-se seguir o mesmo algoritmo dezenas de vezes, usando em cada ocasião vegetais ligeiramente diferentes e obtendo com isso uma sopa ligeiramente diferente. Mas o algoritmo permanece o mesmo. (HARARI, 2016. p. 91-92)

Segundo as teorias neurocientíficas mais sofisticadas não seríamos mais que algoritmos muito complexos. Evidentemente que nossas receitas são muito mais elaboradas porque são o resultado seletivo do processo evolutivo. Até aqui, compreendendo que nossas receitas são tão complexas e que seria muito difícil e improvável reproduzi-las artificialmente, poderíamos crer que ainda somos os soberanos do processo evolutivo, somos o ápice, e que, se inventarmos máquinas super-inteligentes, elas sempre apenas serão máquinas produzidas por nós. Acontece que acatar com a crença de que somos algoritmos significa liberar o caminho na direção dessa complexidade, liberar o caminho para tornar essa complexidade compreensível, por que não a ponto de um dia torná-la reprodutível artificialmente. Uma espécie de segredo do movimento da vida quer ser aqui descoberto e reconhecido. $O$ consenso a respeito de que a vida é um algoritmo, ao liberar o caminho para a exploração dos segredos da vida orgânica, libera a direção do processo evolutivo para além do encadeamento carbônico, exatamente porque o modo de avançar nesse caminho está condicionado à crença de que a vida é, no fim das contas, algoritmo.

Mas uma questão muito importante está relacionada à situação da consciência nesse processo evolutivo. Harari dedica um capítulo de seu livro ao tema do desacoplamento da consciência. O novo "salto evolutivo" está desacoplando a consciência da inteligência. O historiador afirma que não há até o momento (significa, no livro, o ano 2016) a mais remota possibilidade de haver máquinas super-inteligentes $e$ conscientes. Máquinas não apenas capazes de fazer cálculos probabilísticos a uma velocidade assustadora, mas também capazes de experimentarem o sentimento da depressão. Máquinas que considerem, por exemplo, a possibilidade de se suicidar. De uma certa forma, esse salto na direção das máquinas super inteligentes, mas livres do fardo da consciência, anuncia num futuro que não sabemos exatamente dimensionar, a possibilidade de um suicídio da humanidade, não necessariamente por ser muito provável que isso venha a ocorrer de fato com um número crescente de pessoas sensíveis demais para suportar um mundo desumano e pós-humano, mas principalmente porque os humanos do futuro serão tecnologizados para além do condicionamento externo aos aparelhos, que já experienciamos há tempo; seremos cada vez mais misturas de processos 
orgânicos e inorgânicos. Se ainda pudermos falar em seleção natural, será muito natural de ocorrer num futuro próximo, como já ocorre hoje, a emergência de uma raça de humanos superior, melhorada em termos biotecnológicos e cibernéticos. Não se tratará mais de uma perversão sociológica do darwinismo, que tenderia a justificar processos de dominação no campo social pela via do argumento naturalista da seleção natural - "o mais forte e adaptado sobrevive ao mais fraco" - mas de sua própria comprovação nos limites de nossa espécie. E o que torna ainda mais plausível essa hipótese é o desacoplamento da consciência.

De fato, até aqui vivemos em sistemas de crença que, de maneira diversa, pressupunham a aliança entre a inteligência e a consciência. Acreditamos que em geral o animal mais inteligente é também aquele com um grau mais apurado de consciência. Sem que tenhamos nos dedicado a compreender o que é exatamente a inteligência como forma específica de vida, sem que tenhamos meditado suficientemente a respeito do que significa para a própria vida a capacidade de fazer cálculos, estamos nos acostumando cada vez mais com a ideia de que a inteligência pode seguir seu curso evolutivo por fora do canal da consciência.

\begin{abstract}
No passado, havia muitas coisas que somente os humanos podiam fazer. Mas hoje robôs e computadores estão assumindo esse papel e logo poderão sobrepujar os humanos no cumprimento da maioria das tarefas. É verdade que o funcionamento dos computadores é muito diferente do dos humanos, e parece improvável que eles se tornem humanoides em pouco tempo. Em particular, não parece que computadores estejam prestes a ter consciência, nem emoções e sensações. As últimas décadas assistiram a um avanço imenso na inteligência de computadores, mas o avanço na consciência dessas máquinas foi nulo. Até onde sabemos, computadores não são, em 2016, mais conscientes do que seus protótipos na década de 1950. No entanto, estamos à beira de uma grave revolução. Humanos correm o perigo de perder seu valor porque a inteligência está se desacoplando da consciência. (HARARI, 2016. p. 313)
\end{abstract}

A situação é grave porque sequer estamos mantendo, ao mínimo, a capacidade de mensurar a própria gravidade. Há uma espécie muito evidente de encantamento com nossas criações tecnológicas, e até um otimismo consequente. Por enquanto surfamos na onda da tecnologia, sem ter, no entanto, noção do tamanho dela e do que vai acontecer quando ela arrebentar mais adiante, a ponto de ser absorvida pela realidade inteira, a ponto de converter a realidade em um processamento integrado de dado. Uma espécie de cegueira coletiva, muito próxima da situação descrita por José Saramago em seu Ensaio sobre a cegueira, a caverna platônica do avesso: estamos cegos não por falta de luz, mas pelo seu excesso. Uma inevitável decadência moral acompanha essa inteligência que avança independentemente da expansão da consciência. Mas estamos perdendo a própria noção de decadência moral, como os cegos em quarentena no ensaio de Saramago. Aos poucos a máquina deixa de ser projeção de nossa inteligência para se converter em modelo que projeta nossa inteligência.

Desde sempre nos condicionamos aos nossos condicionamentos, todo artifício por nós inventado torna-se, no mesmo instante, um condicionador, portanto um limitador, de nossa próxima ação. Essa é uma explicação arendtiana ( $A$ condição humana): a dimensão da obra, nossa capacidade de construir o mundo em que vamos viver, implica nesse revés do condicionamento em condicionador ${ }^{2}$. Vilém Flusser, em $O$ mundo codificado, vai na mesma

\footnotetext{
2 "A condição humana compreende mais que as condições sob as quais a vida foi dada ao homem. Os homens são seres condicionados, porque tudo aquilo com que eles entram em contato torna-se imediatamente uma condição de sua existência. $O$ mundo no qual transcorre a vita activa consiste em coisas produzidas pelas atividades humanas; mas as coisas que devem sua existência exclusivamente aos homens constantemente condicionam, no entanto, os seus produtores humanos. Além das condições sob as quais a vida é dada ao homem na Terra e, em parte, a partir delas, os homens constantemente criam suas
}

FARIAS, André Brayner de. Sobre animais, humanos e máquinas: para onde vai a consciência? Griot : Revista de Filosofia, Amargosa-BA, v.20, n.2, p.380-392, junho, 2020. 
direção com seu conceito dialético de cultura: o processo cultural, que é o de fabricar objetos que deobstruam o nosso caminho, é também o de obstruir num nível mais elevado nossa suposta evolução tecnológica ${ }^{3}$. Seguindo ainda essa pista conceitual de Flusser, podemos elaborar uma questão fundamental: se é pela criação cultural que delineamos nossa liberdade, que tipo de liberdade estamos criando para nós quando convertemos nossa criação cultural na direção da inteligência desacoplada da consciência? Como escrever um Ensaio sobre a liberdade que não seja uma moral ressentida ${ }^{4}$, um texto conservador, na era da substituição dos processos humanos e conscientes por processos artificiais, muito mais eficientes exatamente porque não conscientes? O desacoplamento da consciência indicaria que estamos abrindo mão da liberdade, na medida em que passamos a crer que nossas ações e decisões derivam de cálculos de probabilidade, e que máquinas artificiais tem capacidade de fazer cálculos de forma muito mais eficiente. Então, delegar nossos processos de decisão a sistemas operacionais passa a ser até mesmo uma questão de inteligência, na medida em que passamos a obter resultados mais seguros e eficazes. Abrir mão da possibilidade de fazer escolhas começa a ser encarado como um problema a menos a resolver, até porque já estamos convencidos de que passamos a errar menos quando entraram em cena os processos artificiais.

Mas será que refletimos suficientemente sobre o que queremos dizer exatamente com as palavras acertar e errar? Considerar que seja dubitável que estejamos progredindo evolutivamente ao investir todo esforço da inteligência na direção dos processos artificiais; duvidar de que isso seja um acerto e não um erro, ou simplesmente que há algo errado em não ver problema no desacoplamento entre a inteligência e a consciência parece ser justamente um efeito de consciência. Efeito de lucidez, se quisermos concordar com Bergson quando diz na Evolução criadora que a consciência é uma espécie de luz que acendemos para deliberar sobre nossas ações. ${ }^{5}$ Em todo caso, tal efeito não chega a ser tamanho a ponto de produzir consequências

próprias condições, produzidas por eles mesmos, que, a despeito de sua origem humana e de sua variabilidade, possuem o mesmo poder condicionante das coisas naturais. $O$ que quer que toque a vida humana ou mantenha uma duradoura relação com ela assume imediatamente o caráter de condição da existência humana. Por isso os homens, independentemente do que façam, são sempre seres condicionados. Tudo o que adentra o mundo humano por si próprio, ou para ele é trazido pelo esforço humano, torna-se parte da condição humana. O impacto da realidade do mundo sobre a existência humana é sentido e recebido como força condicionante. A objetividade do mundo - [...] - e a condição humana complementam-se uma à outra; por ser uma existência condicionada, a existência humana seria impossível sem coisas, e estas seriam um amontoado de artigos desconectados, um não-mundo, se não fossem os condicionantes da existência humana". (ARENDT, 2014. p. 10-11).

3 "Um objeto é algo que está no meio, lançado no meio do caminho (em latim, ob-iectum; em grego, problema). O mundo, na medida em que estorva, é objetivo, objetal, problemático. Um "objeto de uso" é um objeto de que se necessita e que se utiliza para afastar outros objetos do caminho. Há nessa definição uma contradição: um obstáculo que serve para remover obstáculos? Essa contradição consiste na chamada "dialética interna da cultura" (se por "cultura" entendermos a totalidade dos objetos de uso). Essa dialética pode ser resumida assim: eu topo com obstáculos em meu caminho (topo com o mundo objetivo, objetal, problemático), venço alguns desses obstáculos (transformo-os em objetos de uso, em cultura), com o objetivo de continuar seguindo, e esses objetos vencidos mostram-se eles mesmos como obstáculos. Quanto mais longe vou, mais sou impedido pelos objetos de uso (mais na forma de carros e de instrumentos administrativos do que na forma de granizo e tigres). E na verdade sou duplamente obstruído por eles: primeiro, porque necessito deles para prosseguir, e, segundo, porque estão sempre no meio do meu caminho. Em outras palavras: quanto mais prossigo, mais a cultura se torna objetiva, objetal e problemática". (FLUSSER, 2007. p. 194).

${ }^{4}$ Afinal de contas, quem vai ter idéia de bradar pela liberdade de escolha quando estamos tão certos de que máquinas sabem escolher bem melhor que nós?

${ }^{5} \mathrm{O}$ evolucionismo de Bergson enfatiza o papel da consciência no desenvolvimento da vida inteligente. Segundo Bergson, tudo leva a crer que um maior alcance da inteligência acompanha a ampliação da consciência, que não inexiste nas formas rudimentares de vida, mas permanece adormecida. Mas como diferenciamos no bergsonismo a inteligência da consciência? Uma das várias fórmulas empregadas por Bergson em L'évolution créatrice vai dizer da inteligência que ela é "a faculdade de fabricar objetos artificiais, em particular ferramentas para fazer ferramentas, e de variar indefinidamente a fabricação delas" (p. 140). E sobre a consciência, lemos o seguinte: "a consciência é a luz imanente à zona de ações possíveis ou de atividade virtual que envolve a ação efetivamente realizada pelo ser vivo" (p. 145). Evidentemente que inteligência e consciência implicam na questão da liberdade. É livre o ser capaz de variar indefinidamente a criação de suas ferramentas de trabalho, é livre o ser capaz de

FARIAS, André Brayner de. Sobre animais, humanos e máquinas: para onde vai a consciência? Griot : Revista de Filosofia, Amargosa - BA, v.20, n.2, p.380-392, junho, 2020. 
significativas, afinal de contas nada tem impedido o avanço desse suposto processo evolutivo. Estaria nossa consciência geral tão concentrada a ponto de iluminar apenas uma entre tantas ações possíveis? Ou estaríamos compreendendo que a consciência está destinada evolutivamente a ser ultrapassada pela inteligência, pois esta estaria mais que convencida de que passa muito melhor sem o "entulho inútil" da consciência: qual a utilidade de perguntar o que se quer dizer com acerto quando nunca estivemos tão certos sobre acertos e sobre como aperfeiçoar nossa capacidade de acertar? Produzimos máquinas capazes de acertar mais e melhor que nós sem refletir sobre o sentido de acertar, ou dizendo (crendo) que tudo não passa de matemática, ou seja, de algoritmos que calculam os passos necessários de algum procedimento, e que se isso tem ou não sentido passa a ser irrelevante. ${ }^{6}$

Harari aponta que todo esse processo de nossa atual condição tecnológica, e de todas as promessas revolucionárias que aí se inscrevem, está indicando o fim de todo um sistema de crença, que envolve tanto as religiões que pregam que um ser todo-poderoso dá significado ao universo, quanto os humanismos de toda ordem que pregam que o ser humano é a fonte de todo significado. Acreditar na existência de entidades como alma ou na necessidade de haver um eu como instância de tomada de decisão, abrigo da individualidade e da liberdade, são crenças tipicamente humanistas. Mas cada vez importa menos a diferença entre o significado religioso do mundo e o significado científico-humanista diante da virada pós-humanista que estamos prestes a experienciar. ${ }^{7}$ Está mais do que na hora da ciência reconhecer sua dimensão religiosa e da religião reconhecer sua dimensão científica. Até agora tem sido muito confortável e útil a crença de que o lugar da religião é mitológico e dogmático e o da ciência é crítico, racional, questionador, ou de que a verdade séria é a verdade científica porque tem condições de duvidar de si mesma. Essa suposta potencialidade cética do espírito científico está condicionada a uma ordem de poder, como demonstra Michel Foucault. Se uma verdade científica caduca em vista do "progresso crítico da ciência" é porque a "nova verdade" se atualizou melhor ao mecanismo do poder sobre a vida. As análises genealógicas de Michel Foucault esmiúçam esse complexo ciência-biopoder. ${ }^{8}$

antecipar a variedade de ações que pode tomar, compará-las segundo seus interesses e deliberar na direção da melhor ação possível, e também de hesitar diante delas e até paralisar qualquer movimento. É livre o ser que é capaz de escolher o que fazer ou escolher não fazer.

As citações de Bergson referem-se à Edição crítica organizada por Frédéric Worms: BERGSON, Henri. L'évolution créatrice. Paris: Quadrige, PUF, 2013.( A tradução dos trechos é de minha responsabilidade).

${ }^{6}$ A esse respeito, serve de exemplo a experiência de Sally Adee, uma jornalista norte-americana que resolveu se submeter a um procedimento de estimulação transcraniana. $O$ experimento, realizado numa instalação de treinamento de atiradores de elite, consistiu em duas etapas: uma sem o capacete de estimulação transcraniana e outra com o capacete. A jornalista entra numa sala que deve simular um ataque terrorista em massa, várias imagens de homens armados com fuzis e bombas suicidas avançam em sua direção e ela tem que matar o máximo de terroristas que conseguir. Ela relata, no final da primeira etapa, que o pânico gerado pelas imagens dos homens faz com que ela hesite em atirar o tempo todo, ela sai desapontada e se sentindo incompetente. Na segunda etapa, dessa vez com estimulação transcraniana, a situação é completamente diferente: a jornalista relata que perdeu a noção do tempo, que sentiu uma leve tontura e um estranho gosto metálico na boca, mas o resultado é que ela não hesita, não sente medo e consegue eliminar todos os terroristas. $O$ que ela conta após passar pela experiência é bastante revelador: "Nos dias seguintes ela se deu conta de que tinha passado por uma 'experiência quase espiritual... [...]: o que fez o chão sumir foi que, pela primeira vez na minha vida, tudo o que havia na minha cabeça finalmente silenciou... Meu cérebro, livre de inseguranças e dúvidas foi uma revelação"." (HARARI, 2016. p. 292)

7 “[...] o surgimento e a ascensão da ciência tornarão alguns mitos e religiões mais poderosos do que nunca. Para entender por quê, e para enfrentar os desafios do século XXI, deveríamos, portanto, revisitar uma das questões mais perturbadoras entre todas: como é que a ciência moderna se relaciona com a religião? A impressão que se tem é de que já se disse tudo a ser dito sobre essa questão. Mas, na prática, ciência e religião são como marido e mulher que, após quinhentos anos de aconselhamento matrimonial, não se conhecem. Ele ainda sonha com a Cinderela e ela ainda anseia pelo príncipe encantado, enquanto discutem de quem é a vez de levar o lixo para fora". (HARARI, 2016. p. 188)

8 Para uma análise minuciosa da questão em Foucault, remeto o leitor ao Vocabulário de Foucault, de Edgardo Castro, especialmente aos verbetes: disciplina, discurso, dispositivo, poder, saber, verdade, jogo de verdade, vontade de verdade.

FARIAS, André Brayner de. Sobre animais, humanos e máquinas: para onde vai a consciência? Griot : Revista de Filosofia, Amargosa - BA, v.20, n.2, p.380-392, junho, 2020. 
É de dentro do próprio desdobramento do humanismo - que impulsiona o desenvolvimento da ciência biológica e da cibernética, e que, por sua vez, está aliado e condicionado a um ordenamento religioso do mundo ${ }^{9}$ - que a virada pós-humanista está se configurando. $O$ que há de mais significativo nessa virada está associado ao esvaziamento do conceito de liberdade, promovido pelo desacoplamento da consciência. A "consciência desacoplada" do robô super-inteligente, ou seja, a sua ausência de consciência, corresponde a uma consciência em vias de se aposentar sem grandes remunerações, aliás em vias de se reconhecer inútil, excessiva, onerosa, ultrapassada, portanto, em vias de perder o direito à própria voz.

No conto Sono de Haruki Murakami, a mulher que perde a capacidade de dormir adquire - como consequência de seu novo estado, interpretado por ela como uma espécie de novo nascimento ou nova chance evolutiva - uma super-consciência que amplia enormemente suas capacidades intelectuais e físicas. Mas lá no final do relato, a protagonista, reparando a sua condição, chega a uma visão da morte muito reveladora para pensar a virada pós-humanista de nossos tempos: a morte seria uma vigília na escuridão. Conceitualmente falando, o modo habitual com o qual descrevemos a morte como ausência total de consciência e a idéia de uma consciência na total escuridão e no total silêncio dão o mesmo efeito. A morte saberia ser descrita como vigília condenada à perpétua ausência de luz e de som. A virada pós-humanista certamente nos induz ao tema da finitude, mas o desacoplamento da consciência é uma maneira de morrer e não necessariamente desaparecer. É possível que a consciência permaneça sendo, que ela não se atrofie em vista de sua inutilidade, e até que ela possa ser incrementada, ampliada, a ponto de nos tornar mais capacitados nas diversas tarefas que ainda quereremos realizar, mas o que se anuncia com o pós-humanismo cibernético está mais próximo da visão da morte da personagem de Murakami: uma presença a tal ponto recolhida em si mesma que acaba por coincidir com a pura ausência.

Mas se nos resta ainda muita capacidade reflexiva, muita dúvida, muita filosofia, cabe ainda insistir na pergunta: é indubitável considerar que estamos evoluindo quando investimos todo esforço de nossa inteligência, essa faculdade de fabricar instrumentos, na direção da inteligência artificial, ou seja, na direção da inteligência desacoplada da consciência? É indubitável considerar que seja uma evolução o avanço de nossa capacidade tecnológica para a fabricação de máquinas inteligentes, sendo que nenhum avanço houve, e provavelmente não haverá, na fabricação artificial da consciência? Então, se não for possível que máquinas possam ser inteligentes $e$ conscientes, devemos concluir que a consciência não passa de uma poluição mental ${ }^{10}$, perfeitamente e felizmente dispensável? Se for esse o caso, então teremos que admitir que toda ética e toda política, na medida em que dependem de nossas experiências e narrativas conscientes e subjetivas, simplesmente não tem mais sentido. Porque não é apenas o conceito de consciência que está se esvaziando, é também o conceito de liberdade, e, portanto, também o de responsabilidade.

Se adotarmos o ponto de vista da evolução criadora de Bergson, deveríamos crer que se trata muito mais de uma involução, e nem precisaríamos problematizar o fato de que a suposta evolução via inteligência artificial abandona o encadeamento carbônico. Crer numa involução

\footnotetext{
9 “A religião está interessada acima de tudo em ordem. Tem como objetivo criar e manter uma estrutura social. A ciência está interessada acima de tudo no poder. Por meio da pesquisa, tem como objetivo adquirir o poder de curar doenças, fazer guerras e produzir alimento. Como indivíduos, cientistas e sacerdotes podem atribuir imensa importância à verdade, mas, como instituições coletivas, a ciência e a religião preferem respectivamente ordem e poder acima da verdade. Por isso eles são bons companheiros. A busca inabalável da verdade é uma jornada espiritual, que raramente pode ficar confinada aos estamentos religiosos ou científicos". (HARARI, 2016. p. 205)
}

10 Cf. HARARI, 2016. p. 124.

FARIAS, André Brayner de. Sobre animais, humanos e máquinas: para onde vai a consciência? Griot : Revista de Filosofia, Amargosa-BA, v.20, n.2, p.380-392, junho, 2020. 
porque a ausência de consciência, equivalente à consciência sonambúlica dos animais em geral, é o que explica, segundo Bergson, o automatismo no qual a vida animal tende a se encerrar. Considerar que a consciência é coextensiva à vida não deve nos impedir de considerar a radical diferença que caracteriza a consciência humana face à consciência dos animais em geral:

Radical também, consequentemente, é a diferença entre a consciência do animal, mesmo o mais inteligente, e a consciência humana. Pois a consciência corresponde exatamente à potência de escolha de que dispõe o ser vivente; ela é coextensiva à franja de ação possível que envolve a ação real: consciência é sinônimo de invenção e de liberdade. Ora, no animal, a invenção jamais ultrapassa uma variação sobre o tema da rotina. Encerrado nos hábitos da espécie, ele chega sem dúvida a alargá-los por iniciativa individual; mas ele só escapa ao automatismo por um instante, apenas o tempo de criar um automatismo novo: as portas de sua prisão se fecham de novo no mesmo instante em que são abertas; puxando sua própria corrente ele não faz mais que esticá-la. Com o homem, a consciência quebra a corrente. No homem, e somente no homem, ela se liberta (BERGSON, 2013, p.264).

Se o que está para ocorrer, e já ocorre em múltiplas dimensões, é a substituição dos processos humanos de escolha por instâncias artificiais de decisão algorítmica, o automatismo é inevitável. Quando aceito que uma entidade artificial que calcula probabilidades, tome meu lugar nas decisões importantes de minha vida, estou abrindo mão da dúvida, porque obviamente não discutirei com a máquina, já aceitei que ela sabe muito mais de mim do que eu mesmo sei de mim. Aliás, a mesma dúvida que levou Descartes a demonstrar a existência da subjetividade cogitante. A grande vantagem de um animal feroz diante de um ser humano desarmado é uma consciência que não vai hesitar em dar o bote. $O$ animal homem abriu o campo da consciência para além da ação automática. E se quisermos interpretar isso como um aumento da complexidade de fazer cálculos, aumento que resultou num emaranhado de algoritmos, o fato é que hesitamos, duvidamos, nos deprimimos, nos amedrontamos. Tudo isso porque conhecemos de dentro a liberdade, e então começamos a escolher cada caminho a ser tomado, mas sobretudo começamos a inventar caminhos, e percorrer caminhos inventados nem sempre é algo que encoraja. O fato é que variando ou inventando caminhos, fugimos do automatismo. Quer dizer: somos esses para quem a melhor forma de vida está ao alcance da própria mão. De maneira que saltar para uma vida sem consciência, seja do lado da ausência, seja do lado de uma vigília sem qualquer forma de correspondência, como em Murakami, é cair de volta no automatismo, mas dessa vez um automatismo criado por nós, ou seja, que não fomos capazes de alcançar senão pela própria capacidade de invenção, muito consciente. Dessa forma, parece difícil crer que estaríamos evoluindo ao investir nossa capacidade criativa na geração de entidades super-inteligentes, mas incapazes de despertarem a consciência. Parece evidente que não se trata de vida no sentido rigoroso, já que não haverá nada de rigorosamente misterioso, como é o traço de consciência de cada ser vivo; não haverá alteridade no sentido rigoroso, pois por mais surpreendente que seja a máquina inteligente, ela sempre responde a um programa. Não há mistério no programa, há problemas ao alcance de serem resolvidos.

Por isso também, por mais complexa que seja, a máquina não saberá nunca o sentido de se realizar. Ao menos para aquele que conhece a fundo o seu programa, ela se mostrará o que de fato é, uma coisa que faz coisas previsíveis. É cair na ingenuidade imaginar que podemos conversar com uma entidade artificial, porque uma conversa sem consciência é apenas troca de informação. Não se trata de alguém que fala, mas de uma coisa que é capaz de calcular probabilidades e de agilizar o fluxo de informações, no mesmo sentido em que um bom jogador de xadrez movimenta suas peças para dar o cheque-mate. No fundo se trata daquilo que é para

FARIAS, André Brayner de. Sobre animais, humanos e máquinas: para onde vai a consciência? Griot : Revista de Filosofia, Amargosa-BA, v.20, n.2, p.380-392, junho, 2020. 
Bergson a função básica da inteligência: o domínio da matéria, a ação no espaço ${ }^{11}$. Por falta de consciência a máquina não sabe o sentido do tempo, não conhece a duração. Por isso ainda, não pode se realizar, se a realização tem o sentido de promessa, de expectativa, de projeto, e evidentemente, quando ela é apenas o que poderia ter acontecido, também está em relação com a frustração, com o arrependimento, com o fracasso. Obviamente que a cronologia não informa o sentido do tempo.

O roteiro que criamos com as máquinas super-inteligentes força a barra da evolução na medida em que nos leva a crer, ao menos aos mais ingênuos, que o movimento da vida, ou seja, a evolução estaria continuando. A mente artificial é uma exteriorização potencializada da mente humana, e mesmo que passe a dominá-la, não deixará de ser um super-produto da mente humana. Portanto, não há evolução nesse sentido, porque a vida não está seguindo adiante, ao menos a partir do canal humano. Por outro lado, esse roteiro produz de forma surpreendente a nossa animalização, assim como fez, em outro sentido, a teoria evolutiva, quando nos retirou do reinado da criação divina e nos colocou na proximidade parental dos macacos. Seria esse um efeito biopolítico ${ }^{12}$ e pós-histórico ${ }^{13}$. Desse ponto de vista do desacoplamento da consciência - que aqui interpretamos como pura ausência, do lado das máquinas e vigília na escuridão, do lado de cá, ou seja, do lado do vivo - a intuição terá o mesmo efeito do instinto. Lembrando que uma das fórmulas que Bergson cria para imaginar a intuição é essa: a intuição é o instinto que toma consciência de si mesmo ${ }^{14}$. Se não há consciência, a intuição se reduz ao instinto, seja porque nem chega a aparecer, por falta de consciência, seja porque não saberá ser reconhecida, não saberá se comunicar, no caso de haver consciência, só que na escuridão, na ausência. (Talvez a depressão tenha relação com isso: uma consciência na ausência, uma intuição incapaz de se comunicar). Se a intuição se reconverte em instinto e se a inteligência se artificializa, então estamos todos juntos de novo, animais e humanos.

\footnotetext{
11 Outra seria a função da intuição: a compreensão da vida, o conhecimento da duração, ou a compreensão da vida como duração. Máquinas não são e muito provavelmente não serão capazes de intuir.

12 Lembrando que a condição biopolítica para Foucault é a do nosso rebaixamento político para o nível da vida, onde se trata de canalizar a política para a ordem dos problemas vitais, o governo da vida, o controle da população. Também com Hannah Arendt ( $A$ condição humana) podemos chegar ao mesmo ponto, embora ela não utilize o termo biopolítica: quando a diferença entre público e privado não importa mais para entender o político, como conseqüência da elevação da economia ao nível da política (ou mais concretamente, o rebaixamento da política ao nível da economia), estamos de volta à condição de meros animais envolvidos basicamente com o trabalho, ou seja, o esforço visando a satisfação de necessidades.

13 No ensaio Esnobe, de seu livro $O$ aberto - o homem e o animal, Giorgio Agamben relembra a interpretação hegeliana de Alexandre Kojève (Introduction à la lecture de Hegel) sobre a condição pós-histórica da humanidade. A questão fundamental para Kojève, segundo a leitura de Agamben, é que o fim da história determinará o fim da noção de homem, ou seja, nosso retorno à condição animal, o que significará basicamente que assim como os animais, viveremos para nos contentarmos com a satisfação de necessidades. O american way of life seria a antecipação desse futuro pós-histórico. Nesse nível de contentamento voltaríamos a viver, como os animais, num eterno presente, Cf. AGAMBEN, 2017. p. 19-25. Um contraponto interessante aqui é a noção flusseriana de pós-história. Para Vilém Flusser, o advento da imagem-técnica como paradigma comunicacional do nosso tempo, e conseqüentemente a decadência do código escrito (Há futuro para a escrita?), é o anúncio da era pós-histórica. Uma das conseqüências que Flusser gosta de explorar é justamente o embaralhamento entre as noções de natureza e cultura, e embora não seja exatamente nesses termos que Flusser coloque a questão, o fato é que se a cultura tende pós-historicamente a se converter em natureza, perdem sentido todas as idéias que sustentam nossa crença na diferença entre humanos e animais. Recomendo para esse tema a leitura de dois livros de Vilém Flusser: Pós-história - vinte instantâneos e um modo de usar e Natural:mente - vários acessos ao significado de natureza.

14 "O instinto é simpatia. Se essa simpatia pudesse alargar o seu objeto e também refletir sobre ela mesma, nos daria a chave das operações vitais - tal como a inteligência, desenvolvida e disciplinada, nos introduz na matéria. Pois, nunca será demais repetilo, a inteligência e o instinto estão dirigidos em dois sentidos opostos, aquela para a matéria inerte, este para a vida. A inteligência, por intermédio da ciência que é a sua obra, revela-nos de um modo cada vez mais completo o segredo das operações físicas; acerca da vida apenas nos fornece, e, aliás, não pretende mais do que isso, uma tradução em termos de inércia. Ela anda em redor da vida, observando, de fora, o maior número possível de perspectivas sobre ela, atraindo-a para si, em vez de entrar nela. Mas é ao próprio interior da vida que nos conduzirá a intuição, quero dizer o instinto tornado desinteressado, consciente de si próprio, capaz de refletir sobre o seu objeto e de alargá-lo indefinidamente". BERGSON, H. L'évolution créatrice. p. 177-178
}

FARIAS, André Brayner de. Sobre animais, humanos e máquinas: para onde vai a consciência? Griot : Revista de Filosofia, Amargosa - BA, v.20, n.2, p.380-392, junho, 2020. 
O que será, então, nessa perspectiva, a ética animal? O despertar de uma sensibilidade pós-antropocêntrica ou pós-humanista? Ou antes, o receio pós-humanista de algum efeito bumerangue que temos ainda condições de intuir? Efeito bumerangue na medida em que apostar todas as fichas nas entidades artificiais ${ }^{15}$, o que inclui abdicar da consciência e de seus condicionamentos éticos e políticos, significará para nós, cedo ou tarde, o mesmo destino que tiveram e tem os animais, apartados da condição ética pelo exclusivismo humanista e antropocêntrico. Reconhecemos, através das teorias da senciência e do bem-estar animal ${ }^{16}$, que os animais também são capazes de sentir e que tem consciência, ou começamos a sentir na própria pele, antecipando ou intuindo a virada pós-humanista, o que os animais há tempos já sentem, pagando o preço de nossa honrosa dignidade ética, esse alto custo do humanismo, que, no entanto, ainda não havíamos dado a devida atenção? É dubitável que possamos crer numa evolução de nossa sensibilidade quando podemos supor uma sensibilidade antecipada dirigida ainda a nós mesmos. $O$ descentramento humanista está produzindo confusão nas definições que historicamente serviram para nos afastar dos animais, por isso hoje nos voltamos para eles, mas no fundo, como se voltássemos para nós mesmos, para o que finalmente, ou seja, finda a narrativa histórica e humanista, nós somos.

Uma consequência desconcertante dessa redescoberta, de um ponto de vista estritamente biológico, tão óbvia, é que devemos considerar que não estamos exatamente elevando a dignidade ética dos animais, mas rebaixando a nossa própria dignidade ética ao nível dos animais. No fundo, levamos silenciosamente o antropocentrismo dentro da gente. Ele não tem mais o que falar, mas não desapareceu por isso. A nossa atual preocupação com os animais é movida pelo fantasma antropocêntrico, uma espécie de morto-vivo que anima a narrativa da ética animal. Uma entidade que nos habita e sobre a qual insistimos em nos apoiar, ao mesmo tempo que somos encorajados moralmente a afirmar a dignidade ética dos animais. Se aceitamos que devemos reconhecer os animais como subjetividades éticas, temos que admitir, ainda que isso não possa se realizar porque os animais não falam nossa língua, a possibilidade de os animais nos reconhecerem, já que o reconhecimento é mútuo. Nesse ponto, começa a perder sentido a diferença entre humanos e animais. Se nos tornamos capazes de reconhecer eticamente os animais, é porque nos reconhecemos como iguais a eles. Mas não haveria uma certa ingenuidade em querer continuar chamando isso de ética? Será que refletimos suficientemente sobre a dependência das narrativas históricas, como a ética, da diferença e da separação entre humanos racionais e animais irracionais? Nosso condicionamento ético está articulado à diferença e à nossa superioridade com relação aos animais, e não é simples nem óbvio querer simplesmente ignorar ou suspender, quando não é o caso de desconhecer, esse condicionamento.

A ética animal tem seu fundo biopolítico. Se a biopolítica é, em geral, a condição política rebaixada ao nível da satisfação de nossas necessidades vitais, que evidentemente vão se corroendo até beirarem o nível mais rasteiro da vida; se a biopolítica não é a vida que se eleva à necessidade política, mas a política que se rebaixa às necessidades da vida, também não é a ética animal o passaporte de entrada para que os animais participem conosco da maravilhosa

\footnotetext{
15 Segundo Harari, tal investimento poderá configurar na emergência de dois tipos novos de religião, o tecnohumanismo, que seria a crença na idéia de que os humanos, uma vez tendo cumprido seu destino histórico, se quiserem permanecer no jogo das máquinas devem atualizar seus "sistemas operacionais", o que resultaria numa raça de humanos melhorada tecnologicamente: para o tecnohumanismo humanos serão misturas de processos orgânicos e artificiais; e o dataísmo, a religião dos dados, que prega a desobstrução de todos os canais de informação, ou seja, a liberdade total do fluxo de informações, que deve conectar e comandar absolutamente todas as coisas, inclusive os animais humanos (ver nota 2). Recomendo a esse respeito a leitura dos dois últimos capítulos do livro Homo Deus de Harari: O oceano da consciência e $A$ religião dos dados.

${ }_{16}$ Abordei essas teorias no artigo Ética para o meio ambiente, em TORRES, J. C. B. (Org.). Manual de ética - questões de ética teórica e aplicada. Petrópolis, Caxias do Sul: Vozes, EDUCS. 2014. p. 604-623
} 
comunidade dos seres éticos, mas antes a nossa animalização pós-histórica, antes o nosso (improvavelmente admissível) retorno ao nível em que nossas necessidades e as dos animais são exatamente as mesmas.

A biologia informa a economia (e informar significa condicionar a forma), no sentido de descrever a vida como essa matéria orgânica fadada a suprir necessidades. A economia descreve as leis que devem reger o suprimento das necessidades, o nomos da casa. Por sua vez, a economia informa a política. A biopolítica é a forma da política quando essa passa a ser regida pelas leis da economia. A questão é decidir se essa é ainda uma forma política no sentido rigoroso da distinção da coisa pública e da coisa privada, no sentido, portanto, da separação da economia, o reino privado e caseiro do suprimento de necessidades, e da vida livre, que não precisa se ocupar do provimento de necessidades porque está suficientemente ocupada dos assuntos que interessam na esfera pública ${ }^{17}$ (e dado que o suprimento de necessidades deveria ser simplesmente pressuposto). Em outra direção, que vai levar ao mesmo efeito biopolítico e póshistórico, a biologia também informa a cibernética: ela fornece os modelos bioquímicos de fabricação de algoritmos artificiais. E seguimos adiante, reformando pouco a pouco o nosso sistema de crença e fortalecendo uma espécie de neuro-consenso, unificando a base sobre a qual todas as disciplinas vão reconfigurando seu discurso ${ }^{18}$. Esse neuro-consenso ameaça a consciência, marginalizando ou esvaziando o conceito sobre o qual assentam as condições de nosso apego humanista: valores, liberdade, experiências subjetivas, dignidade ética, dignidade da vida política (e não biopolítica).

\section{Conclusão: para onde vai a consciência?}

Para onde vai a consciência? Certamente que as inteligências artificiais não serão oneradas com problemas éticos, isso dependeria do avanço artificial da consciência. Se hoje observamos uma retomada de fôlego do discurso ético-filosófico expandindo-se para novas áreas de problematização: bioética, ética ambiental, ética animal, e a despeito de ter que reconhecer que essa retomada de fôlego é um efeito biopolítico, como tentamos demonstrar, é preciso também reconhecer o trabalho de consciência que envolve e pressupõe todo novo discurso ético. A questão é decidir até onde estamos dispostos a articular criticamente esse trabalho, que ainda deve ir longe. $\mathrm{O}$ reconhecimento do fundo biopolítico e do clima pós-histórico onde se desdobram os novos discursos não pretende desencorajar, por exemplo, a defesa ética dos animais e da natureza. Muito pelo contrário: a força de tal defesa depende de sua maturidade crítica. E é exatamente essa maturidade crítica da consciência que deve tornar possível a recuperação de uma potência criadora suficientemente ativa, ou seja, suficientemente consciente para não se deixar encantar pelos produtos de sua própria criação, como é o caso do encantamento e da

\footnotetext{
17 "Viver uma vida inteiramente privada significa, acima de tudo, estar privado de coisas essenciais a uma vida verdadeiramente humana: estar privado da realidade que advém do fato de ser visto e ouvido por outros, privado de uma relação 'objetiva' com eles decorrente do fato de ligar-se e separar-se deles mediante um mundo comum de coisas, e privado da possibilidade de realizar algo mais permanente que a própria vida." (ARENDT, 2014. p. 71)

18 "É claro que, ainda que o dataísmo esteja errado e os organismos não sejam apenas algoritmos, isso não impedirá necessariamente que o dataísmo tome conta do mundo. Muitas religiões anteriores adquiriram enorme popularidade e poder apesar de seus erros factuais. Se o cristianismo e o comunismo puderam fazer isso, porque não o dataísmo? O dataísmo, especialmente, tem boas perspectivas porque se dissemina por todas as disciplinas científicas. Um paradigma científico unificado pode facilmente tornar-se um dogma incontestável. É muito difícil contestar um paradigma científico, mas até agora nenhum só deles foi adotado por todo o estamento científico. De onde resulta que os estudiosos de um campo sempre puderam importar visões heréticas externas. Mas se cada um, de musicólogos a biólogos, usar o mesmo paradigma dataísta, as excursões interdisciplinares servirão apenas para fortalecer ainda mais o paradigma. Como resultado, mesmo que o paradigma fosse falho, seria extremamente difícil resistir a ele". (HARARI, 2016. p. 396)
} 
cegueira que envolve nossa relação com as máquinas inteligentes. Se não for para investir na potência crítica e criadora do trabalho de consciência que ainda persiste e ainda pode ter vida longa, a depender exatamente dessa potência, estaremos fadados a produzir de forma reativa e ressentida todo novo discurso ético, até o último suspiro da consciência. 


\section{Referências}

AGAMBEN, Giorgio. O aberto - o homem e o animal. Rio de Janeiro: Civilização Brasileira, 2017. ARENDT, Hannah. A condição humana. Rio de Janeiro: Forense Universitária, 2014.

BERGSON, Henri. L'évolution créatrice. Paris: Quadrige, PUF, 2013.

CASTRO, Edgardo. Vocabulário de Foucault - um percurso pelos seus temas, conceitos e autores. Belo Horizonte: Autêntica, 2016.

FLUSSER, Vilém. Pós-história - vinte instantâneos e um modo de usar. São Paulo: Annablume, 2011.

FLUSSER, Vilém. O mundo codificado - por uma filosofia do design e da comunicação. São Paulo: Cosac Naify, 2007.

FLUSSER, Vilém. Natural:mente - vários acessos ao significado de natureza. São Paulo: Annablume, 2011.

FLUSSER, Vilém. A escrita - há futuro para a escrita? São Paulo: Annablume, 2010.

FOUCAULT, Michel. Vigiar e punir. Petrópolis: Vozes, 2009.

FOUCAULT, Michel. História da sexualidade 1 - a vontade de saber. São Paulo: Graal, 2009.

FOUCAULT, Michel. Arte, epistemologia, filosofia e história da medicina. Rio de Janeiro: Forense Universitária, 2011. (Col. Ditos e escritos VII)

HARARI, Yuval Noah. Homo Deus - uma breve história do amanhã. São Paulo: Companhia das Letras, 2016.

MURAKAMI, Haruki. Sono. Rio de Janeiro: Alfaguara, 2015.

TORRES, João Carlos Brum (Org.). Manual de ética - questões de ética teórica e aplicada. Petrópolis; Caxias do Sul: Vozes; EDUC, 2014.

Autor(a) para correspondência: André Brayner de Farias, Rua Francisco Getúlio Vargas, 1130, Petrópolis, 95070 560, Caxias do Sul - Rs, Brasil. abraynerfarias@yahoo.com 